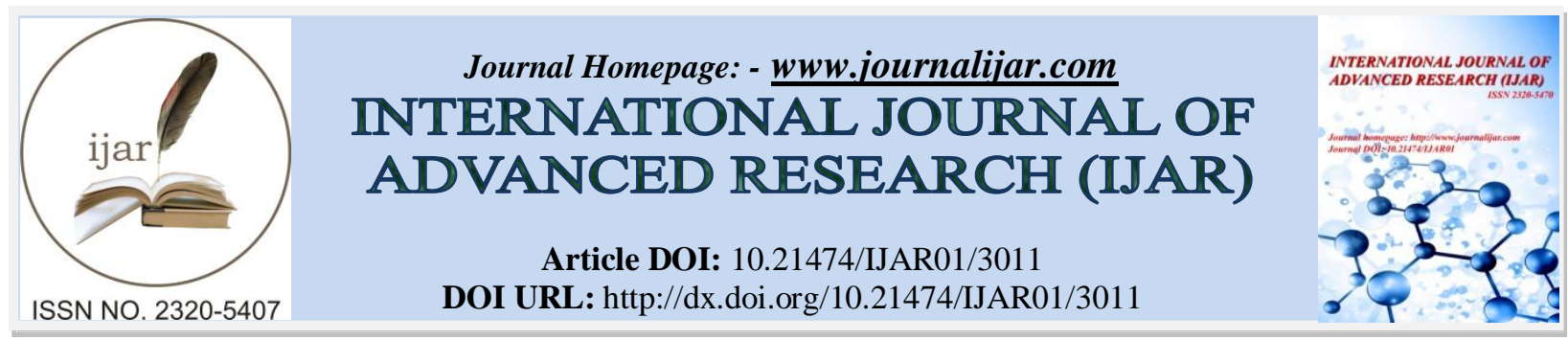

RESEARCH ARTICLE

\title{
CERVICOFACIAL TERRATOMA IN NEWBORN BABY-AN UNUSUAL TUMOR.
}

Dr. Rajul Iqbal Desai ${ }^{1}$, Dr. Nidhi Shailesh Soni ${ }^{2}$, Dr. Iqbal Mohammad Desai ${ }^{3}$ and Kunjlata Rajput ${ }^{4}$.

1. Consultant Histopathologist,G.R.M.I. ,Rajasthan Hospital,Ahmedabad ,Gujarat.

2. Consultant Pathologist, G.R.M.I. ,Rajasthan Hospital,Ahmedabad ,Gujarat.

3. H.O.D, G.R.M.I. ,Rajasthan Hospital,Ahmedabad, Gujarat.

4. Quality Manager, G.R.M.I. ,Rajasthan Hospital,Ahmedabad ,Gujarat.

\section{Manuscript Info}

Manuscript History

Received: 29 November 2016

Final Accepted: 27 December 2016

Published: January 2017

\begin{abstract}
Teratomas are tumors consisting of tissues derived from all three germs cell layers: endoderm, mesoderm, and ectoderm, in different proportions. There are often solid and cystic components to the mass.If the neoplastic tissue is uniformly mature, the tumor is termed Mature terratoma. The presence of any immature tissue with an embryonal appearance warrants a designation of immature terratoma. Cervical teratomas are rare, found once in every 20,000 births. They can block the baby's esophagus and affect the baby's ability to swallow amniotic fluid. This can lead to an increase in the fluid level around the baby (polyhydramnios). Increased fluid can lead to preterm labor. Cervical teratomas have increased blood flow which can result in fetal heart failure (hydrops).The cervical teratoma is a rare entity. Its prognosis mostly depends on the risk of neonatal respiratory distress, its extension and potential malignancy. Surgical management must be as complete as possible to avoid recurrences and malignant transformation. We present a case of a cervicofacial teratoma in an infant with total excision and cure.
\end{abstract}

Copy Right, IJAR, 2016,. All rights reserved.

\section{Introduction:-}

A twenty five days old male child weighing $2.54 \mathrm{kgs}$, admitted with cystic swelling at the left side of neck as well as face. CBC shows neutrophilic leucocytosis ,CRP level raised $-29.19 \mathrm{mg} / \mathrm{dl}$. AFP levels is more than $400 \mathrm{IU} / \mathrm{ml}$. Provisional diagnosis was made either Lymphangioma or Dermoid cyst. Although the patient remained asymptomatic except slight dyspnea. In my case the patient belongs to low socioeconomic category from a remote area so antenatal ultrasound was not done thereby detected at birth only. On local examination, there was a solitary left neck mass which was irregular, of size about $10 \times 7 \mathrm{~cm} 2$, soft cystic to firm consistency,nontender,local temperature not raised,visible veins present,overlying skin is smooth and more firm on lower part of the swelling. MRI showed a $11 \times 8 \times 4 \mathrm{~cm} 3$ mass, with solid and cystic components with contralateral airway displacement. CT scan revealed tumoral calcifications. The infant underwent surgical excision and the specimen was sent for histopathological examination. The infant was discharged without any particular complaints.Gross examination shows a greyish white cystic structure measuring $10 \times 7 \times 3 \mathrm{~cm} 2$, outer surface is partly nodular with hard consistency.Microscopy shows predominantly solid with areas of cystic changes. Multiple sections studied from tumor showed mature as well as immature elements derived from all 3 germ layers. Mature elements comprised of 
glands, mature cartilage, and neural tissue and foci of calcification. Immature elements included neuroepithelial elements, neuroectodermal rosettes, and immature cartilage. Final diagnosis was immature cervical teratoma with no evidence of malignancy.

\section{Discussion:-}

Cervical teratomas are rare neoplasms found once in every 20,000 births. Teratomas are the most common congenital tumor $1-3,11$. The most common location of terratomas is sacrococcygeal followed by intracranial. 5\% of fetal teratomas are located in the cervical region7,12 Fetal teratomas consist of ectodermal, endodermal and mesodermal germ-cell tissue including neuroepithelial tissue. Mature and immature teratomas are distinguished by the degree of differentiation of the tissue. The differential diagnosis of fetal cervical teratoma includes cystic hygroma,lymphangioma, hemangioma, cervical meningocele, thyroglossal duct cyst, esophageal diverticula, dermoid cyst, brachial cleft cyst, epignathus and congenital goiter13.Usually a teratoma is often a non-threatening mass;however, the malignant transformation of fetal cervical teratomas has been reported. Ultrasound diagnosis is done in early pregnancy which help in planning the surgery thereby preventing complications . The sonographic findings of cervical teratomas typically include solid and cystic structures within a heterogeneous mass. In up to $50 \%$ of cases calcifications might be seen within the mass while cartilage or bone tissue is less common 14 . The extent of vascularization can be assessed by Doppler flow imaging. Magnetic resonance imaging has also been described as providing essential information about the localization and diagnosis of giant fetal neck masses. MRI showed a 11x8x4 cm 3 mass, with solid and cystic components with contralateral airway displacement.The tumor was capsulated and not infiltrating the surrounding tissues. It was completely excised. At birth ,patient was stable with slight slight dyspnoea,The alpha fetoprotein (AFP) level was elevated at $400 \mathrm{IU} / \mathrm{ml}$. Immature cells produce a protein called alpha-fetoprotein (AFP) which can be monitored with a blood test. AFP levels in the blood are used as a screening tool to check for tumor regrowth, in addition to regular check-ups and imaging.CBC shows neutrophilic leucocytosis ,CRP level raised $-29.19 \mathrm{mg} / \mathrm{dl}$. Pathological examination revealed an immatureteratoma, which consisted of a mixture of tissue such as embryonic cartilage,immature mesenchymal substrate, endodermal glands, respiratory epithelial and immature neuroepithelial tissue with necrosis A teratoma with immature cells presents a small risk of recurrence.

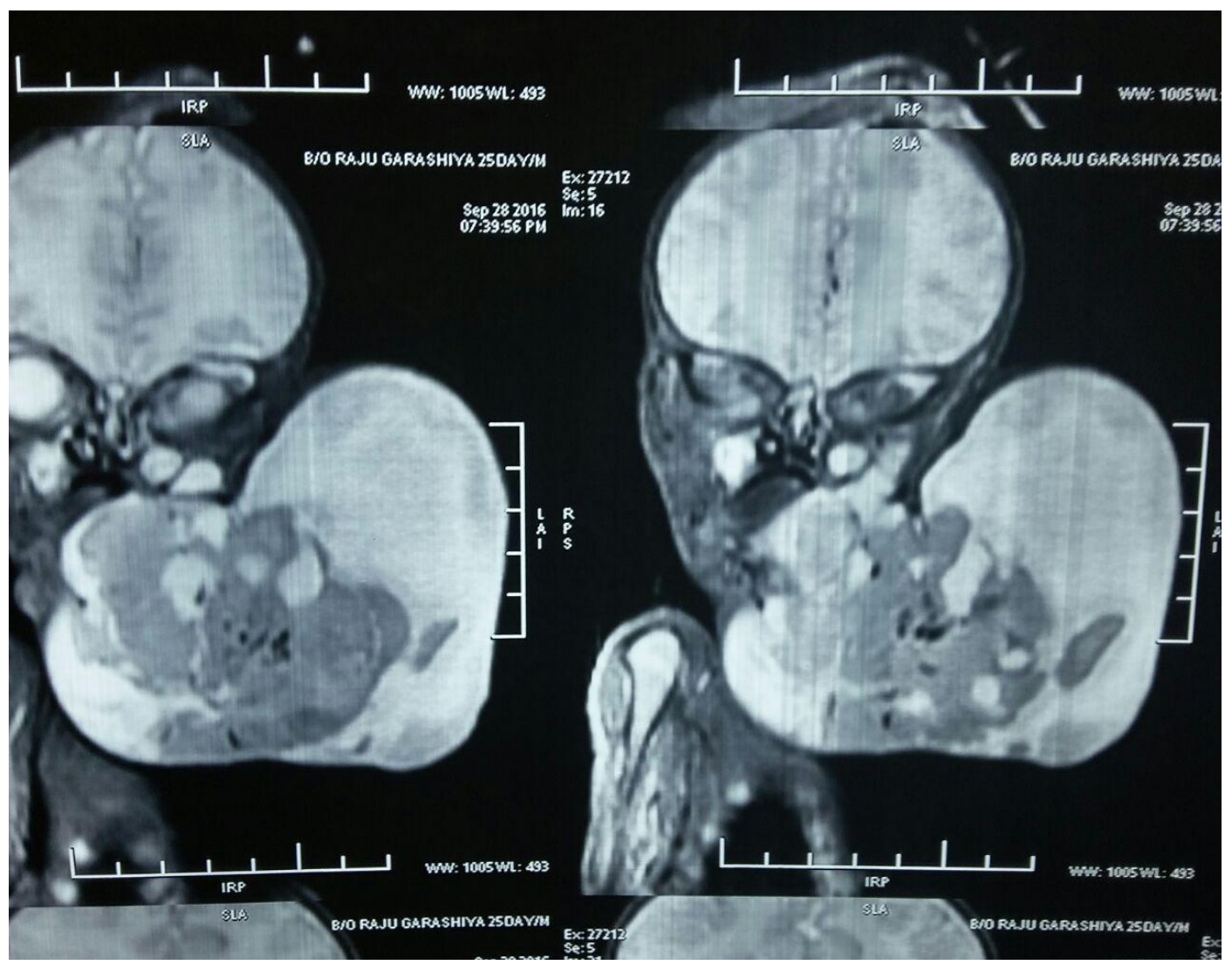




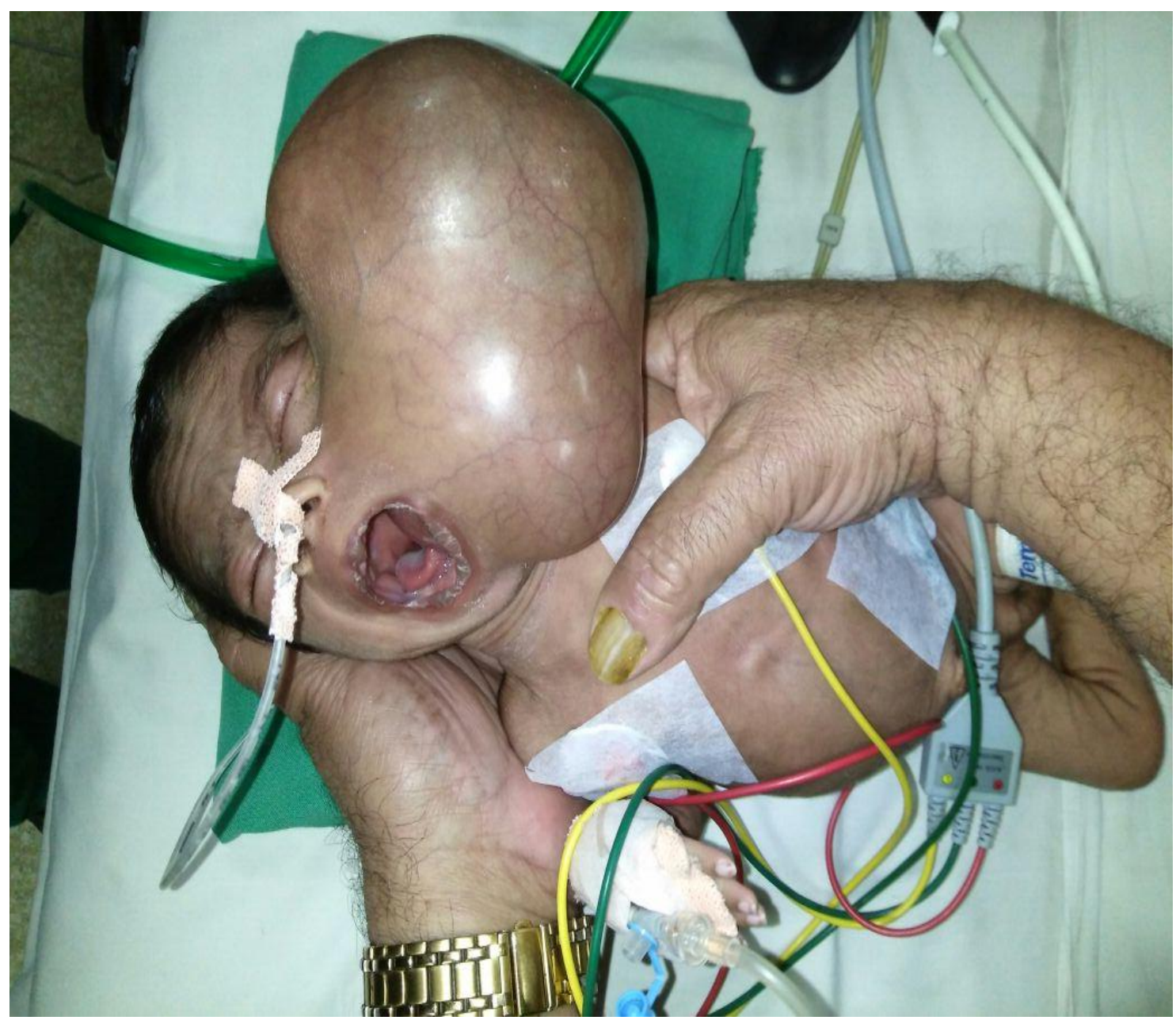

\section{Conclusion:-}

Cervical terratomas are rare entity mostly presenting at birth.antenatal diagnosis can be done with the help of ultrasound,MRI,CT scan and AFP levels.Although they are benign but in some cases malignant transformation can occur.Airway obstruction and esophageal compression can occur.Complete surgical excision is done to cure the patient.

\section{References:-}

1. Jordan RB, Gauderer MWL. Cervical teratomas: an analysis. Literature review and proposed classification. $J$ Pediatr Surg 1988; 23: 583-91.

2. Gundry SR, Wesley JR, Klein MD, Barr M, Coran AG. Cervical teratomas in the newborn. J Pediatr Surg 1983; 18: 382-6.

3. Trecet JC, Claramunt V, Larraz J, Ruiz E, Zuzuarregui M, Ugalde FJ.Prenatal ultrasound diagnosis of fetal teratoma of the neck. J Clin, Ultrasound 1984; 12: 509-11.

4. Isaacs H, Jr. Perinatal (fetal and neonatal) germ cell tumors. J Pediatr Surg. 2004;39(7):1003-13.

5. Tonni G, De Felice C, Centini G, Ginanneschi C. Cervical and oral teratoma in the fetus: a systematic review of etiology, pathology, diagnosis, treatment and prognosis. Arch Gynecol Obstet. 2010;282(4):355-61.

6. Figueiredo G, Pinto PS, Graham EM, Huisman TA. Congenital giant cervical teratoma: pre- and postnatal imaging. Fetal Diagn Ther. 2010;27(4):231-2. 
7. Langer JC, Tabb T, Thompson P, Paes BA, Caco CC. Management of prenatally diagnosed tracheal obstruction: access to the airway in utero prior to delivery. Ther 1992; 7: 12-16.

8. Daskalakis G, Efthimiou T, Pilalis A, et al. Prenatal diagnosis and management of fetal pharyngeal teratoma: a case report and review of the literature. J Clin Ultrasound 2007;.35: 159-163.

9. Azizkhan RG, Haase GM, Applebaum H, Dillon PW, Coran AG, King PA, et al. Diagnosis, management, and outcome of cervicofacial teratomas in neonates: A Childrens Cancer Group study. J Pediatr Surg 1995;30:312-6. 